\title{
Stressors, coping styles, and anxiety \& depression in pediatric nurses with different lengths of service in six tertiary hospitals in Chengdu, China
}

\author{
Huiling Liao^, Wei Tang^, Yuanyuan Huang^, Mei Liu^, Ying Zhang^, Lei Zhang^, Tao Ai^ \\ Department of Pediatric Respiratory Medicine, Chengdu Women's and Children's Central Hospital, School of Medicine, University of Electronic \\ Science and Technology of China, Chengdu, China \\ Contributions: (I) Conception and design: H Liao; (II) Administrative support: T Ai; (III) Provision of study materials or patients: H Liao; (IV) \\ Collection and assembly of data: Y Huang, W Tang; (V) Data analysis and interpretation: H Liao, Y Huang, W Tang, M Liu; (VI) Manuscript \\ writing: All authors; (VII) Final approval of manuscript: All authors. \\ Correspondence to: Yuanyuan Huang. Department of Pediatric Respiratory Medicine, Chengdu Women's and Children's Central Hospital, School of \\ Medicine, University of Electronic Science and Technology of China, Chengdu, China. Email: 154031698@qq.com.
}

\begin{abstract}
Background: The level of stress experienced by nurses is related to their length of service. In the current study, we investigated the potential correlations among stressors, coping styles, and anxiety and depression in pediatric nurses with different lengths of service in six tertiary hospitals in Chengdu, Sichuan, China.

Methods: Between January and June 2018, we enrolled 500 pediatric nurses from 6 tertiary hospitals in Chengdu using a convenience sampling method. A cross-sectional survey was carried out using the Chinese Nurses' Occupational Stressor Scale (NOSS), the Simplified Coping Style Questionnaire (SCSQ), and Zung's Self-rating Anxiety Scale (SAS) and Self-rating Depression Scale (SDS).

Results: Statistically significant differences were found in the average scores of NOSS and scores of various dimensions, SAS and SDS, and Simple Coping Style score among pediatric nurses with different lengths of service (all $\mathrm{P}<0.05$ ). Nurses with $8-12$ years of service had the highest average score for stressors. Anxiety and depression were both prevalent among nurses with 4-7 years of service. The average overall stress scores of nurses with different lengths of service were negatively correlated with positive coping style $(\mathrm{P}<0.05)$, were not significantly correlated with negative coping style $(\mathrm{P}>0.05)$, and were positively correlated with anxiety score and depression score $(\mathrm{P}<0.05)$. The positive coping style score showed negative correlations with anxiety score and depression score (both $\mathrm{P}<0.05$ ). The negative coping style score was positively correlated with the scores for anxiety and depression (all $\mathrm{P}<0.05$ ), except in nurses with $4-7$ years of service, for whom the negative coping style score showed no significant correlation with the depression score.

Conclusions: Pediatric nurses with different lengths of service in tertiary hospitals in Chengdu experience different levels of workplace stress. Pediatric nurses with 4-7 and 8-12 years of service have higher levels of workplace stress and are more likely to experience anxiety and depression.
\end{abstract}

Keywords: Pediatric nurses; length of service; stressors; coping styles; anxiety; depression.

Submitted Nov 13, 2020. Accepted for publication Dec 21, 2020.

doi: $10.21037 / \mathrm{tp}-20-439$

View this article at: http://dx.doi.org/10.21037/tp-20-439

\footnotetext{
^ ORCID: Huiling Liao, 0000-0003-1244-3274; Wei Tang, 0000-0001-8811-4798; Yuanyuan Huang, 0000-0002-8818-139X; Mei Liu, 0000-00026069-2761; Ying Zhang, 0000-0002-2483-4400; Lei Zhang, 0000-0001-6598-9014; Tao Ai, 0000-0003-3882-3590.
} 


\section{Introduction}

Workplace stress is prevalent among nurses (1). Rapid transformation of Biomedical model, competitive healthcare markets, and continuously increasing needs and awareness of rights among patients present huge challenges for nursing professionals. For reasons including the working style and environment, family expectations, and social concerns associated with treating child patients $(2,3)$, even there is a high incidence of violence in the workplace (4). Pediatric nurses are especially susceptible to workplace stress and mental health problems than nurses in other wards (3), such as internal medicine, surgery and emergency departments (5). Empirical evidence has shown that occupational stress can be reduced (6). A variety of coping styles or strategies can be adopted to help nurses to deal with stress and its influencing factors. Coping strategies can eliminate negative emotions, thereby protecting the individual's physical and psychological health (7). Coping style is an intermediary mechanism that regulates stress and mental health. The manner in which an individual copes with stress is critical to their psychological state. Positive coping styles are conducive to enhancing the psychological adaptability of nurses, while negative coping styles exacerbate burnout, resulting in a poor emotional state (8-10). The research showed that the positive and negative coping styles of pediatric nurses in grade III hospitals were higher than those in grade II hospitals, indicating that pediatric nurses in grade III hospitals adopted more positive coping styles and more negative coping styles when facing difficulties (11).

Studies have shown that the stress experienced by nurses is related to their length of service $(2,12)$; however, few articles have explored stressors among pediatric nurses with different lengths of service. Therefore, we conducted a cross-sectional survey among pediatric nurses in six tertiary hospitals in Chengdu, Sichuan, China, in an attempt to identify the stressors, coping styles, and anxiety and depression among pediatric nurses with different lengths of service, to assist the development of effective measures for stress relief in pediatric nurses, and to improve the quality and performance pediatric nursing services. We present the following article in accordance with the SURGE reporting checklist (available at http://dx.doi.org/10.21037/tp-20-439).

\section{Methods}

\section{Subjects}

Between January and June 2018, we performed a cross- sectional survey of nurses working in pediatric wards in 2 children's hospitals and 4 general hospitals in Chengdu using a convenience sampling method. The inclusion criteria for participants were as follows: licensed as a nurse practitioner; (II) working in clinical setting; and (III) participating in the survey voluntarily. Nurses who were on leave or who submitted their resignation during the survey were excluded. The study was conducted in accordance with the Declaration of Helsinki (as revised in 2013). The study was approved by ethics board of Chengdu Women and Children Center Hospital and informed consent was taken from all individual participants.

\section{Research methods}

A questionnaire-based survey was conducted. The survey tools employed included: (I) a general information form. Items on the self-designed form included the participant's gender, age, marital status, education, income, professional title, employment status, number of night shifts, length of service, and the situation of the participant's children. (II) The Chinese Nurses' Occupational Stressor Scale (NOSS) enveloped by $\mathrm{Li}$ et al. (13). The scale comprises 35 items across 5 dimensions: nursing profession and job, time allocation and workload, work environment and resources, patient nursing and management, and interpersonal relationships. Stress rates on a 4-point Likert scale, from 1 point (low stress) to 4 points (high stress). The test-retest correlations of these 5 dimensions ranges from $0.71-0.86$, and the test-retest correlation of the entire scale is 0.79 (14). (III) Simple Coping Style Scale: The Simplified Coping Style Questionnaire (SCSQ) developed by Xie et al. (15). The scale consists of 20 items in 2 dimensions: positive coping style (items 1 to 12 ) and negative coping style (items 13 to 20), which were rated using a 4-point (0-3 points) scoring system. The higher the positive coping style score, the milder the participant's mental problems and symptoms, and the higher the negative coping style score, the more severe the participant's mental problems and symptoms. The content validity index (CVI) of the scale is 0.89 , and the Cronbach's $\alpha$ coefficient is 0.90 (2). Zung's Self-rating Anxiety Scale (SAS) (16) and Self-rating Depression Scale (SDS) (17). Each scale includes 20 items, with each item scored on a scale of 1-4 (1-4 points). The standard score is calculated by multiplying the total score by 1.25 . The cutoff values of the SAS and SDS standard scores are 50 points and 53 points, respectively. A score below the cut-off value is considered to indicate an absence of anxiety or depression 
Table 1 General information of 500 pediatric nurses

\begin{tabular}{|c|c|c|c|}
\hline Item & Group & $\begin{array}{l}\text { Number of } \\
\text { respondents }\end{array}$ & $\begin{array}{l}\text { Proportion } \\
\text { (\%) }\end{array}$ \\
\hline \multirow[t]{4}{*}{ Age (years) } & $>25$ & 152 & 30.4 \\
\hline & $26-30$ & 187 & 37.4 \\
\hline & $31-35$ & 58 & 11.6 \\
\hline & $\geq 36$ & 103 & 20.6 \\
\hline \multirow{4}{*}{$\begin{array}{l}\text { Years of service } \\
\text { in pediatric } \\
\text { department } \\
\text { (years) }\end{array}$} & $\leq 3$ & 180 & 36.0 \\
\hline & $4-7$ & 172 & 34.4 \\
\hline & $8-12$ & 58 & 11.6 \\
\hline & $\geq 13$ & 90 & 18.0 \\
\hline \multirow[t]{4}{*}{$\begin{array}{l}\text { Education } \\
\text { background }\end{array}$} & $\begin{array}{c}\text { Technical secondary } \\
\text { school }\end{array}$ & 24 & 4.8 \\
\hline & Junior college & 260 & 52.0 \\
\hline & Undergraduate & 213 & 42.6 \\
\hline & Master & 3 & 0.6 \\
\hline \multirow{4}{*}{$\begin{array}{l}\text { Professional } \\
\text { title }\end{array}$} & Nurse & 208 & 41.6 \\
\hline & Senior nurse & 209 & 41.8 \\
\hline & Nurse supervisor & 76 & 15.2 \\
\hline & Deputy director & 7 & 1.4 \\
\hline \multirow[t]{2}{*}{ Siblings } & None & 260 & 52.0 \\
\hline & Yes & 240 & 48.0 \\
\hline \multirow[t]{2}{*}{ Job category } & Daytime shift nurse & 213 & 42.6 \\
\hline & Night shift nurse & 287 & 57.4 \\
\hline \multirow[t]{2}{*}{ Gender } & Male & 1 & 0.2 \\
\hline & Female & 499 & 99.8 \\
\hline
\end{tabular}

symptoms, while a higher score denotes a more severe mental problem.

\section{Survey methods}

After the permission of the nursing departments of the six hospitals had been obtained, the investigators distributed the questionnaire forms to the participants on the day of the survey. The purpose, content, and filling method of the questionnaire was explained to the survey participants before the investigation. Informed consent was obtained from the participants, who filled out the questionnaire independently and then submitted it to the investigator. The questionnaire recovery rate was $100 \%$ (531 of
531). Questionnaires that were incomplete or invalid were excluded, including those with $>20 \%$ of questions with missing answers or answers with obvious reaction tendencies. Finally, effective responses were obtained from 500 subjects (effective response rate: $94.16 \%$ ).

\section{Statistical analysis}

Statistical analyses were performed using SPSS 20.0 software (IBM, USA). Count data were expressed using proportions, and measurement data were presented using $\bar{x} \pm$ standard deviation (SD). Analysis of variance (ANOVA) was performed for inter-group comparisons. The NOSS, SCSQ, and SAS/SDS scores were analyzed using Spearman's correlation analysis. $\mathrm{P}<0.05$ was considered to be statistically significant.

\section{Results}

\section{General data of survey participants}

In total, 500 pediatric nurses were included in the final analysis. Their general information is summarized in Table 1.

\section{Stressors of pediatric nurses with different lengths of service}

Statistically significant differences existed among nurses with different lengths of service in terms of the average scores of nurses' stressors and the scores of five different various dimensions from the NOSS (all $\mathrm{P}<0.05$ ). Nurses with $8-12$ years of service had the highest average score for stressors (Table 2).

\section{Comparisons of anxiety \& depression and coping style scores among pediatric nurses with different lengths of service}

As shown in Table 3, the scores for anxiety and depression significantly differed among pediatric nurses with different lengths of service, as did the Simple Coping Style Scale score (all $\mathrm{P}<0.05)$.

\section{Comparisons of the proportions of anxiety \& depression among pediatric nurses with different lengths of service}

A total of 481 questionnaires were eligible for the analysis of anxiety score, 475 questionnaires for the analysis of depression score, and 456 questionnaires for the analysis of 
Table 2 Comparison of average scores for stressors among pediatric nurses with different lengths of service

\begin{tabular}{|c|c|c|c|c|c|c|c|}
\hline Item & $\begin{array}{l}\text { Nursing profession } \\
\text { and job }\end{array}$ & $\begin{array}{l}\text { Time allocation and } \\
\text { workload }\end{array}$ & $\begin{array}{l}\text { Work environment } \\
\text { and resources }\end{array}$ & $\begin{array}{l}\text { Patient nursing } \\
\text { and management }\end{array}$ & $\begin{array}{l}\text { Interpersonal } \\
\text { relationships }\end{array}$ & Total stress & $\begin{array}{c}\text { Order of total } \\
\text { stress }\end{array}$ \\
\hline$\leq 3$ years & $2.40 \pm 0.63$ & $2.56 \pm 0.73$ & $2.42 \pm 0.79$ & $2.63 \pm 0.63$ & $2.00 \pm 0.75$ & $2.35 \pm 0.57$ & 4 \\
\hline $8-12$ years & $2.46 \pm 0.64$ & $2.89 \pm 0.76^{a}$ & $2.79 \pm 0.77^{\mathrm{a}}$ & $2.59 \pm 0.60$ & $2.41 \pm 0.77^{\mathrm{ab}}$ & $2.53 \pm 0.56$ & 1 \\
\hline$\geq 13$ years & $2.24 \pm 0.65^{\mathrm{b}}$ & $2.88 \pm 0.79^{\mathrm{a}}$ & $2.81 \pm 0.85^{\mathrm{a}}$ & $2.56 \pm 0.66^{\mathrm{b}}$ & $2.02 \pm 0.65^{c}$ & $2.35 \pm 0.60$ & 3 \\
\hline$F$ value & 2.705 & 8.807 & 7.038 & 3.224 & 4.796 & 3.418 & \\
\hline$P$ value & 0.045 & 0.000 & 0.000 & 0.018 & 0.003 & 0.017 & \\
\hline
\end{tabular}

${ }^{\mathrm{a}}, \mathrm{P}<0.05$, compared with $\leq 3$ years group; ${ }^{\mathrm{b}}, \mathrm{P}<0.05$, compared with $4-7$ years group; ${ }^{\mathrm{c}}, \mathrm{P}<0.05$, compared with $8-12$ years group.

Table 3 Comparisons of anxiety \& depression scores and Simple Coping Style Scale score among pediatric nurses with different lengths of service

\begin{tabular}{lcccc}
\hline Item & Positive coping score & Negative coping score & Anxiety score & Depression score \\
\hline$\leq 3$ years & $24.23 \pm 6.39$ & $9.28 \pm 3.92$ & $39.74 \pm 10.17$ & $42.67 \pm 10.08$ \\
$4-7$ years & $22.31 \pm 6.82^{\mathrm{a}}$ & $10.43 \pm 4.15^{\mathrm{a}}$ & $42.92 \pm 10.43^{\mathrm{a}}$ & $45.82 \pm 10.41^{\mathrm{a}}$ \\
$8-12$ years & $23.48 \pm 6.66$ & $11.80 \pm 4.57^{\mathrm{a}}$ & $43.46 \pm 12.57$ & $44.44 \pm 11.81$ \\
$\geq 13$ years & $24.99 \pm 6.30^{\mathrm{b}}$ & $11.57 \pm 4.22^{\mathrm{a}}$ & $39.88 \pm 9.86$ & $41.31 \pm 9.80^{\mathrm{b}}$ \\
Total sample & $23.61 \pm 6.62$ & $10.37 \pm 4.23$ & $41.30 \pm 10.61$ & $43.72 \pm 10.47$ \\
F value & 3.999 & 8.969 & 3.898 & 4.471 \\
P value & 0.008 & 0.000 & 0.009 & 0.004 \\
\hline
\end{tabular}

${ }^{\mathrm{a}}, \mathrm{P}<0.05$, compared with $\leq 3$ years group; ${ }^{\mathrm{b}}, \mathrm{P}<0.05$, compared with $4-7$ years group.

both scores. The proportions of both anxiety and depression were high among nurses with 4-7 years of service and differed significantly from the proportions in the $\leq 3$ years' service group and $\geq 13$ years' service group (both $\mathrm{P}<0.05$; Figure 1).

\section{Correlations among stressors, coping style, and anxiety \& depression in pediatric nurses}

The average total stress scores of nurses with different lengths of service were negatively correlated with positive coping style $(\mathrm{P}<0.05)$ and were not significantly correlated with negative coping style $(\mathrm{P}>0.05)$; however, they did show a positive correlation with anxiety score and depression score $(\mathrm{P}<0.05)$. The positive coping style score was negatively correlated with the anxiety score and depression score (both $\mathrm{P}<0.05$ ). The negative coping style score was positively correlated with the anxiety and depression scores, except in nurses with 4-7 years of service, for whom the negative coping style score showed no significant correlation with the depression score (all $\mathrm{P}<0.05)$ (Table 4).

\section{Discussion}

Workplace stress is a reaction that occurs when demands are placed on workers to meet job requirements that do not match their knowledge, skills, or abilities, which challenges their coping capabilities (18). Many factors can affect an individual's workplace stress levels, including personal cognitive evaluation, personality, and previous physical and mental experience, In addition, some literatures also proposed, mineralocorticoid receptors (MR) would also be important in stress coping, adaptation and depression $(19,20)$. We believe this is because MR can be seen as one of nature's tools to effectively coordinate the appraisal of and coping with changes in our environment (21-23). Nurses have poorer mental health than the general population (24). In particular, anxiety and depression are commonly reported 

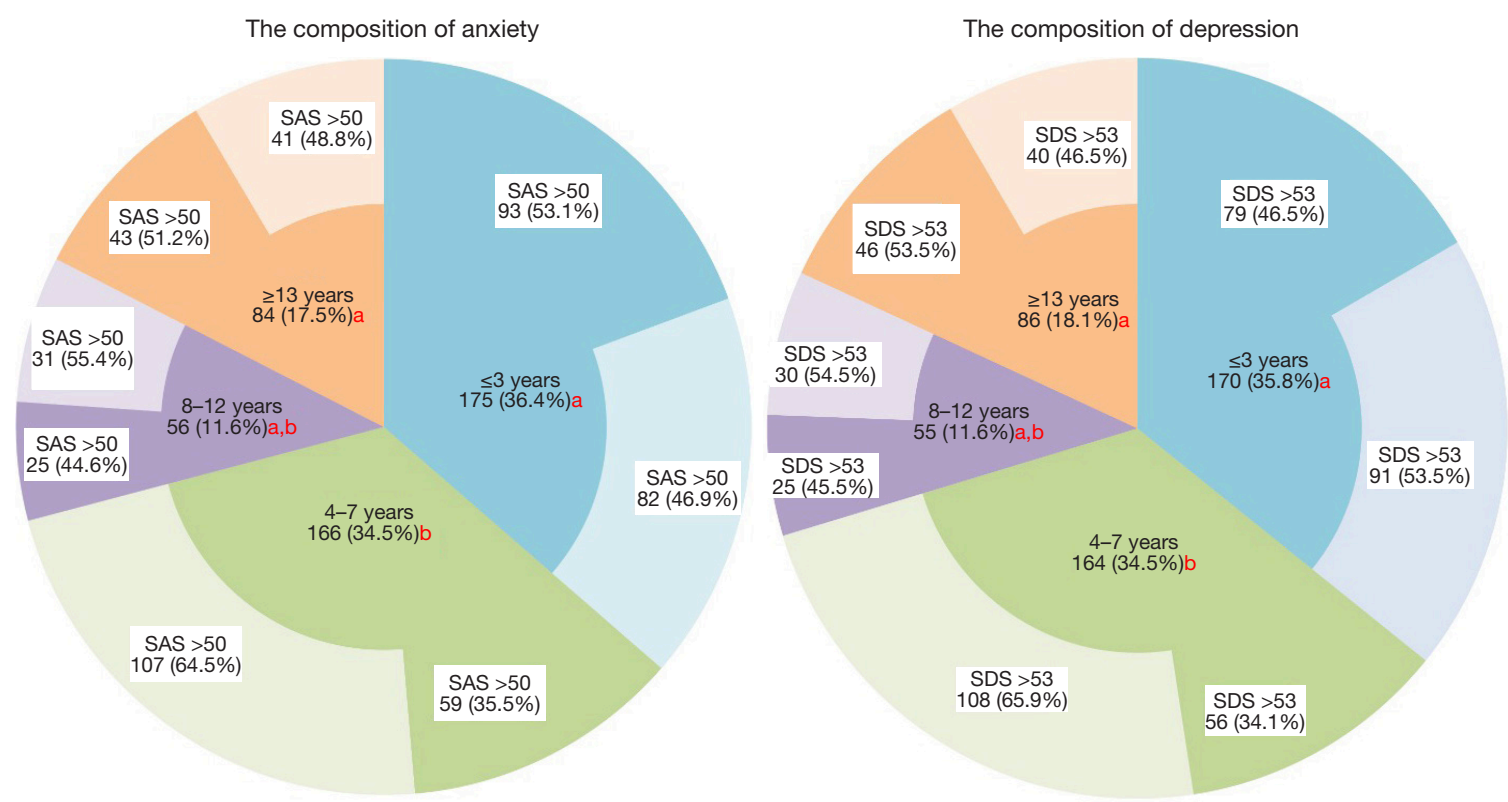

Figure 1 Comparisons of the proportions of anxiety \& depression among pediatric nurses with different lengths of service. There is no statistically significant difference between a and $\mathrm{a}$, between $\mathrm{a} / \mathrm{b}$ and $\mathrm{a}$, or between $\mathrm{b}$ and $\mathrm{a} / \mathrm{b}$, whereas the difference between a and $\mathrm{b}$ is statistically significant. $\chi^{2}=11.853$ for anxiety $(\mathrm{P}<0.05) ; \chi^{2}=4.029$ for depression $(\mathrm{P}<0.05)$.

Table 4 Correlations among stressors, coping style, and anxiety \& depression scores in pediatric nurses ( $\mathrm{r}$ value)

\begin{tabular}{|c|c|c|c|c|c|}
\hline Length of service & Item & Positive coping score & Negative coping score & Anxiety score & Depression score \\
\hline \multirow{2}{*}{$\leq 3$ years } & Positive coping score & - & - & -0.427 & -0.529 \\
\hline & Negative coping score & - & - & 0.289 & 0.235 \\
\hline \multirow[t]{2}{*}{$4-7$ years } & Average total stress score & -0.162 & $0.066^{\mathrm{a}}$ & 0.513 & 0.455 \\
\hline & Negative coping score & - & - & 0.178 & $0.063^{\mathrm{a}}$ \\
\hline \multirow[t]{3}{*}{$8-12$ years } & Average total stress score & -0.152 & $-0.007^{a}$ & 0.529 & 0.526 \\
\hline & Positive coping score & - & - & -0.422 & -0.528 \\
\hline & Negative coping score & - & - & 0.179 & 0.18 \\
\hline$\geq 13$ years & Negative coping score & - & - & 0.269 & 0.298 \\
\hline
\end{tabular}

${ }^{\mathrm{a}}, \mathrm{P}>0.05$.

mental health problems among nurses, and the prevalence rates of depression, anxiety, and stress are $32.4 \%, 41.2 \%$, and $41.2 \%$, respectively (25). Our analysis of the stressors, coping style, and anxiety and depression scores of nurses with different lengths of service showed that nurses with $\leq 3$ years of service had the lowest total stressor score and negative coping score, and their positive coping score was relatively high. In contrast, Nayeri et al. (26) and Boonrod et al. (27) failed to observe any significantly correlation between stress levels and the length of service. Pediatric 
nurses with a length of service of less than 3 years are often more energetic and enthusiastic, with a stronger capacity to withstand and cope with stress, than nurses with a longer length of service. Daily work is supervised by a superior nurse They have no family burden and have strong support from family members. Promotion is not an issue for them, and they are willing to spend more time and energy on work, so that they can advance in their careers more quickly. They have positive expectations of their work, working environment, and interpersonal relationships. Therefore, these nurses have a more positive attitude toward work, and their overall stress is not high. Further analysis of the various stressors revealed that nurses with $\leq 3$ years of service had the highest stress score in patient management, which may be related to the fact that junior pediatric nurses have less experience, fewer skills, and lack communication skills as well as a comprehensive and systematic understanding of patients' conditions. Moreover, diverse and complicated disease conditions, poor cooperation from children, and the high expectations of parents can also increase the stress felt by junior nurses during patient management, which is further exacerbated by the inability of pediatric patients to communicate their condition. Therefore, adequate training should be offered to these nurses to improve their nursing capabilities, communication skills, and working performance, thus promoting a positive coping style and enhancing professional identity.

Pediatric nurses with a length of service of 4-7 and 812 years had higher stress scores. The scores for time allocation and workload showed significant differences compared with those of nurses with $\leq 3$ years of service. Furthermore, these 2 groups had higher scores and proportions of anxiety and depression and lower positive coping scores. Nurses in these 2 groups are in the stages of enhancing their experience and skills. As the backbone of nursing in the clinical first-line setting, they are required to solve challenging problems in clinical nursing and do well in training. They are also responsible for taking care of children and their families, and providing continuous services. Sometimes, they are also expected to participate in scientific research. It is necessary for them to consider their own professional development and to communicate fully with department managers. In terms of their personal life, they may also need to manage other commitments, such as marriage, childbirth, supporting elderly relatives, and educating their own children. For shift workers, fatigue is often accompanied by depression and anxiety (28). Pediatric nurses with a length of service of 4-12 years face considerable stress especially in terms of time allocation and workload, which can easily lead to mood swings, anxiety, and depression. In a supportive clinical team, members may feel safe to express their emotions and share their stories with others $(29,30)$. Quattrin et al. (31) have shown that where there has not been sufficient collegial support, this lack of support has contributed to the burnout of some oncology nursing staff in Italy. Hospital managers should offer adequate psychological counseling for nurses with 4-12 years of service and develop time management courses to support them to organize their time efficiently or Establish multiple communication channels. Also, managers should understand the difficulties in life and establish stable social support systems, so that these nurses can be more positive and active at work. Moreover, they should provide more personal development opportunities, which will enable nurses to participate more in management and develop their own career plans.

Nurses with a length of service of $\geq 13$ years had the highest positive coping score and lowest depression score. Their stress score was lower than that of the 4-7 years group and the 8-12 years group, which suggests that more experienced employees experience less professional stress (12), as described by Dargahi et al. (32). Nurses with $\geq 13$ years of service have already accumulated rich clinical experience and life experience, and achieved career promotion. Most of them have a stable family life. They have also learned how to face and handle stress,

Correlation analysis revealed that the total stress score of pediatric nurses with different lengths of service was positively correlated with the scores for anxiety and depression. Furthermore, the positive coping score was negatively correlated with the total stress score and the anxiety and depression scores, and the negative coping score was positively correlated with the anxiety and depression scores. Thus, nurses with higher stressor scores tend to have more severe anxiety and depression. Workplace stressors and coping styles are key factors affecting nurses' anxiety, depression, and other negative emotions. Workplace stress adversely affects nurses'physical and mental health (33-35). In our current study, the correlation between the total stress scores of pediatric nurses with different lengths of service and the negative coping score was not statistically significant $(\mathrm{P}>0.05)$, which indicated that the stress levels of pediatric nurses with different lengths of service did not change with the alternation in negative coping. The possible explanation for this may be that some sources of stress are objective and cannot eliminated by a change in coping style. Moreover, when an individual believes that they cannot cope with an 
issue in a specific situation, they may adopt some negative coping strategies such as the contents from SCSQ "trying to temporarily leave the problem behind by taking a break or vacation", "trying to forget the whole thing", "accepting the reality because there is no other choice", and comforting themselves, which, to a certain extent, may protect the individual from the negative impact of life stressors.

In conclusion, pediatric nurses with different lengths of service in tertiary hospitals in Chengdu experience different levels of workplace stress. Pediatric nurses with 4-12 years of service have higher workplace stress and are more likely to experience anxiety and depression. Stress in nurses is correlated with positive coping score and anxiety and depression scores. Pediatric nurses should understand the impact of workplace stress on their mental wellbeing, be aware of the stressors, pay adequate attention to their physical and mental health, avoid negative emotions such as anxiety and depression by positive coping style, and Meanwhile, nursing managers should make workplace stress a top priority and adopt effective measures to relieve the stress felt by pediatric nurses, taking into account their length of service. These measures may minimize stress and protect the physical and mental health of pediatric nurses, thus improving their enthusiasm for their work and, consequently, the quality of nursing.

\section{Limitations}

This study is a preliminary investigation, there are some deficiencies: In terms of research area and participants, there were only selected the tertiary hospitals of Chengdu, and no other tertiary hospitals of the city and township hospitals and community hospitals nurses, also failed to compare pediatric doctor's stress research,; In terms of research content, there is no further research on the physiological factors that influence and control stress and depression. In terms of research methods, only the crosssectional research method of questionnaire survey was adopted, but mixed research prevention was not adopted for verification and further follow-up. Therefore, in the further study, pediatric medical workers in different types of hospitals will be investigated, and related physiological indicators will be combined with follow-up observation, so as to obtain more dynamic research results.

\section{Acknowledgments}

Funding: None.

\section{Footnote}

Reporting Checklist: The authors have completed the SURGE reporting checklist. Available at http://dx.doi. org/10.21037/tp-20-439

Data Sharing Statement: Available at http://dx.doi. org/10.21037/tp-20-439

Conflicts of Interest: All authors have completed the ICMJE uniform disclosure form (available at http://dx.doi. org/10.21037/tp-20-439). The authors have no conflicts of interest to declare.

Ethical Statement: The authors are accountable for all aspects of the work in ensuring that questions related to the accuracy or integrity of any part of the work are appropriately investigated and resolved. The study was conducted in accordance with the Declaration of Helsinki (as revised in 2013). The study was approved by ethics board of Chengdu Women and Children Center Hospital and informed consent was taken from all individual participants.

Open Access Statement: This is an Open Access article distributed in accordance with the Creative Commons Attribution-NonCommercial-NoDerivs 4.0 International License (CC BY-NC-ND 4.0), which permits the noncommercial replication and distribution of the article with the strict proviso that no changes or edits are made and the original work is properly cited (including links to both the formal publication through the relevant DOI and the license). See: https://creativecommons.org/licenses/by-nc-nd/4.0/.

\section{References}

1. Wheeler HH. A review of nurse occupational stress research: 1. Br J Nurs 1997;6:642-5.

2. Sharma P, Davey A, Davey S, et al. Occupational stress among staff nurses: Controlling the risk to health. Indian J Occup Environ Med 2014;18:52-6.

3. Pikó B. Work-related stress among nurses: a challenge for health care institutions. J R Soc Promot Health 1999;119:156-62.

4. Maslach C, Schaufeli WB, Leiter MP. Job burnout. Annu Rev Psychol 2001;52:397-422.

5. Zhong XQ, Chen CY, Deng DM, et al. Investigation on nurses' work stress and subjective well-being in different departments of basic hospitals. Henan Medical Research 
2019;28:3668-70.

6. Richardson KM, Rothstein HR. Effects of occupational stress management intervention programs: a meta-analysis. J Occup Health Psychol 2008;13:69-93.

7. Malak JS, Safdari R, Zeraati H, et al. An agent based architecture for high-risk neonate management at neonatal intensive care unit. Electron Physician 2018;10:6193-200.

8. Ceslowitz SB. Burnout and coping strategies among hospital staff nurses. J Adv Nurs 1989;14:553-8.

9. Ding Y, Yang Y, Yang X, et al. The Mediating Role of Coping Style in the Relationship between Psychological Capital and Burnout among Chinese Nurses. PLoS One 2015;10:e0122128.

10. Folkman S, Lazarus RS, Gruen RJ, et al. Appraisal, coping, health status, and psychological symptoms. J Pers Soc Psychol 1986;50:571-9.

11. Weng DC, Huang XF, Zhang ZF, et al. Investigation on mental health status and coping styles of pediatric nurses in different levels of hospitals. Journal of Shenyang Medical College 2020;22:451-4.

12. Sharma N, Takkar P, Purkayastha A, et al. Occupational Stress in the Indian Army Oncology Nursing Workforce: A Cross-sectional Study. Asia Pac J Oncol Nurs 2018;5:237-43.

13. Li XM, Liu YJ. Job stressors and burnout among staff nurses. Chinese Journal of Nursing 2000;35:645

14. Yuan Y, Yu H, Xu XF. Reliability and validity of the Chinese Nursing Stressor Scale. Chinese Journal of Nursing Education 2007;(05):195-8.

15. Xie YN. A preliminary study on the reliability and validity of Simple Coping Style Scale. Chinese Journal of Clinical Psychology 1998;(02):3-5.

16. Zung $W W$. A rating instrument for anxiety disorders. Psychosomatics 1971;12:371-9.

17. Zung WW. A self-rating depression scale. Arch Gen Psychiatry 1965;12:63-70.

18. Dewa CS, Lin E, Kooehoorn M, et al. Association of chronic work stress, psychiatric disorders, and chronic physical conditions with disability among workers. Psychiatr Serv 2007;58:652-8.

19. Herman JP, Figueiredo H, Mueller NK, et al. Central mechanisms of stress integration: hierarchical circuitry controlling hypothalamo-pituitary-adrenocortical responsiveness. Front Neuroendocrinol 2003;24:151-80.

20. Belujon P, Grace AA. Regulation of dopamine system responsivity and its adaptive and pathological response to stress. Proc Biol Sci 2015;282.

21. Joëls M, Sarabdjitsingh RA, Karst H. Unraveling the time domains of corticosteroid hormone influences on brain activity: rapid, slow, and chronic modes. Pharmacol Rev 2012;64:901-38.

22. Joëls M, Karst H, DeRijk R, et al. The coming out of the brain mineralocorticoid receptor. Trends Neurosci 2008;31:1-7.

23. ter Heegde F, De Rijk RH, Vinkers CH. The brain mineralocorticoid receptor and stress resilience. Psychoneuroendocrinology 2015;52:92-110.

24. Khamisa N, Oldenburg B, Peltzer K, et al. Work related stress, burnout, job satisfaction and general health of nurses. Int J Environ Res Public Health 2015;12:652-66.

25. Maharaj S, Lees T, Lal S. Prevalence and Risk Factors of Depression, Anxiety, and Stress in a Cohort of Australian Nurses. Int J Environ Res Public Health 2018;16.

26. Nayeri ND, Salehi T, Noghabi AA. Quality of work life and productivity among Iranian nurses. Contemp Nurse 2011;39:106-18.

27. Boonrod W. Quality of working life: perceptions of professional nurses at Phramongkutklao Hospital. J Med Assoc Thai 2009;92 Suppl 1:S7-15.

28. Ruggiero JS. Correlates of fatigue in critical care nurses. Res Nurs Health 2003;26:434-44.

29. Ekedahl M, Wengström Y. Nurses in cancer care--coping strategies when encountering existential issues. Eur J Oncol Nurs 2006;10:128-39.

30. Fitch MI, Matyas Y, Robinette M. Caring for the caregivers: Innovative program for oncology nurses. Can Oncol Nurs J 2006;16:110-22.

31. Quattrin R, Zanini A, Nascig E, et al. Level of burnout among nurses working in oncology in an Italian region. Oncol Nurs Forum 2006;33:815-20.

32. Dargahi H, Changizi V, Jazayeri Gharabagh E. Radiology employees' quality of work life. Acta Med Iran 2012;50:250-6.

33. Laposa JM, Alden LE, Fullerton LM. Work stress and posttraumatic stress disorder in ED nurses/personnel. J Emerg Nurs 2003;29:23-8.

34. Chang EM, Bidewell JW, Huntington AD, et al. A survey of role stress, coping and health in Australian and New Zealand hospital nurses. Int J Nurs Stud 2007;44:1354-62.

35. McKinney BK. Withstanding the pressure of the profession. J Nurses Staff Dev 2011;27:69-73.

Cite this article as: Liao H, Tang W, Huang Y, Liu M, Zhang Y, Zhang L, Ai T. Stressors, coping styles, and anxiety \& depression in pediatric nurses with different lengths of service in six tertiary hospitals in Chengdu, China. Transl Pediatr 2020;9(6):827-834. doi: 10.21037/tp-20-439 